Check for updates

Cite this: RSC Adv., 2017, 7, 31875

Received 5th February 2017

Accepted 13th June 2017

DOI: 10.1039/c7ra01472d

rsc.li/rsc-advances

\section{Characteristics of soy protein isolate/gum arabic- stabilized oil-in-water emulsions: influence of different preparation routes and $\mathrm{pH}$}

\begin{abstract}
Xiangzhen Kong, (D) Cong Jia, Caimeng Zhang, Yufei Hua and Yeming Chen
The properties of oil-in-water emulsions containing soy protein isolate (SPI) with or without gum arabic (GA) have been studied under different $\mathrm{pH}$ and different preparation routes. Three routes were used for the preparation of emulsions ( $10 \%(\mathrm{w} / \mathrm{v})$ oil and $0.5 \%(\mathrm{w} / \mathrm{v}) \mathrm{SPI}$ with or without $0.5 \%(\mathrm{w} / \mathrm{v}) \mathrm{GA})$. In emulsions I, $\mathrm{SPI}$ solution with/without GA were first $\mathrm{pH}$ adjusted followed by homogenization with oil; in emulsions II, the oil was directly emulsified with SPI-GA coacervates at pH 4.0 to form the 'mixed emulsions', then $\mathrm{pH}$ was adjusted; in emulsions III, GA was added to a SPI-stabilized emulsion followed by $\mathrm{pH}$ adjustment. The results showed that $\mathrm{pH}$ adjustment before or after homogenization with oil greatly influenced the droplet size and emulsifying stability whether for the SPI emulsions or SPI/GA emulsions. The emulsions III showed much slower flocculation rate and higher emulsifying stability at $\mathrm{pH} 4.0-7.0$. The microstructures of SPI-GA emulsion III were more uniform, with the comparably smallest $d_{43}$ values in the presence of SDS. It could be indicated that the preparation routes of emulsions greatly influenced the stability of SPI-control emulsion or SPI-GA emulsion.
\end{abstract}

\section{Introduction}

Emulsions are widely used in cosmetics, pharmaceuticals, and food industries because lipophilic bioactive compounds can be encapsulated in oil droplets to increase their solubility and stability in the aqueous phase. ${ }^{1}$ Milk protein and soy protein are preferably used as emulsifiers in the food industry. ${ }^{2}$ Soy protein is an abundant byproduct of the soybean oil industry and has good functionalities for food processing. ${ }^{3}$ The protein adsorption layers in the oil-water interface prevent the drop-drop coalescence and then stabilize the emulsions. ${ }^{4}$ However, protein-stabilized emulsions are highly sensitive to environmental stresses such as $\mathrm{pH}$, ionic strength and temperature. ${ }^{5-7}$ When the $\mathrm{pH}$ approaches the isoelectric point of the protein and/or salt concentration is higher in the emulsion, the electrostatic repulsion of the protein adsorption layers decreases and therefore coalescence and flocculation happen. ${ }^{8}$

The emulsion stability depends on the factors such as emulsifier surface coverage and surface charge density, as well as emulsifier layer thickness and bulk physicochemical conditions. It is reported that the stability of protein emulsion can be improved by protein-polysaccharide complex formed by electrostatic attraction..$^{9-11}$ The polysaccharide can change the charges as well as increase the thickness of the interfacial

State Key Laboratory of Food Science and Technology, School of Food Science and Technology, Jiangnan University, 1800 Lihu Avenue, Wuxi 214122, Jiangsu Province, People's Republic of China. E-mail: xzkong@jiangnan.edu.cn; Fax: +86-051085329091; Tel: +86-0510-85329091 layers, enhancing the hydrophilicity and steric repulsion of the droplets. For example, the addition of negatively charged polysaccharides interacting with positively charged proteins may form a thick layer at the interface which prevents coalescence. The behavior of charged polysaccharides added to proteinstabilized oil-in-water emulsions depends on the pH. For example, at a pH below the isoelectric point of the protein the negatively charged pectin interacts via electrostatic interactions with $\beta$-lactoglobulin absorbed at the interface. McClements and Li (2010) have found that the emulsion stability can be improved by adding polysaccharide, forming an interfacial complex with the adsorbed protein layer after homogenization, i.e., forming "bilayer" or "layer-by-layer" coated droplets. ${ }^{1}$ The emulsions containing multilayer-coated droplets are more stable than those containing bilayer-coated droplets. ${ }^{5}$ Soy soluble polysaccharides are shown to prevent destabilization of SPI-based oil-in-water $(\mathrm{O} / \mathrm{W})$ emulsions under acidic conditions. $^{12}$

A number of different preparative routes have been explored to form stabilized oil-in-water emulsions and 'order of addition' effects have been shown to be important. ${ }^{13}$ Emulsions stabilized by electrostatic polysaccharide-protein complexes can be formed in different ways. Traditionally, emulsions have been prepared using premixed coacervates. Weinbreck, Minor and Kruif (2004), for example, used whey protein-gum arabic complex coacervates to encapsulate flavor oils. ${ }^{\mathbf{1 4}}$ They reported that the best capsules are formed at the $\mathrm{pH}$ for maximum coacervation and maximum viscosity. Another approach is to form an emulsion using a protein as a primary emulsifier and 
then to add a polysaccharide to adsorb onto the protein layer forming a bilayer. The increase in adsorbed polymer layer thickness and likely increase in zeta potential will tend to stabilize the emulsion by inhibiting droplet aggregation through enhanced electrosteric repulsions. Emulsions produced using this procedure have been shown to have enhanced stability in respect of ionic strength and $\mathrm{pH}^{15}$

In the present study, two biopolymers (soy protein isolates, SPI and gum arabic, GA) have been chosen to stabilize oil-inwater emulsions. SPI is mainly composed of $\beta$-conglycinin (7S) and glycinin (11S). The former is a glycoprotein composed of three subunits, $\alpha, \alpha^{\prime}$, and $\beta$, whereas the latter is a hexamer of acidic and basic subunit pairs connected by one disulfide bond. ${ }^{16}$ Both glycinin and $\beta$-conglycinin have emulsifying ability and are capable of stabilizing emulsions by lowering the interfacial tension between water and oil. ${ }^{17} \mathrm{GA}$ is widely utilized in food production as a soluble dietary fiber. GA is an arabinogalactan-type polysaccharide, which is composed of six carbohydrate moieties and a protein fraction and can be considered as a weak polyelectrolyte. ${ }^{18}$ The major fraction of GA consists of $\beta$-(1-3) galactopyranose polysaccharide backbone that is highly branched with $\beta-(1-6)$ galactopyranose residues terminating in arabinose and glucuronic acid and/or 4- $O$ methyl glucuronic acid units. ${ }^{19}$ GA has a $\mathrm{p} K_{\mathrm{a}}$ value of about 3 due to its ionized carboxylic groups along the backbone. GA is negatively charged in mildly acidic solution. Previously, we characterized the complexing behavior between SPI and GA by isothermal titration calorimetry (ITC), turbidity, sedimentation and ternary phase boundaries. ${ }^{20}$ However, knowledge of emulsifying properties of soy proteins/gum arabic is far away from its application at acidic environment.

The understanding of protein-polysaccharide interactions is fundamental in predicting the stability and rheology of emulsions. The objective of this research was to investigate the influence of different preparation routes, $\mathrm{pH}$ and addition of GA on the stability of SPI-stabilized emulsions. And the mean droplet diameter, microstructure, droplet surface coverage, $\zeta$ potential and rheological properties were evaluated.

\section{Materials and methods}

\subsection{Materials}

Defatted low-denatured soybean meal (protein content, 52.4\% (w/w), dry basis) was provided by Shandong Wonderful Co., Ltd. (Dongying, China). Gum arabic (crude protein: $2.19 \%$, moisture: $10.72 \%$, ash: $3.32 \%$, w/w) was purchased from Sinopharm Chemical Reagent Co., Ltd. (Shanghai, China). Nile Red and Fluorescein isothiocyanate (FITC) were purchased from SigmaAldrich (St. Louis, Mo). Soybean oil was obtained from a local supermarket. Other reagents and chemicals used in this study were of analytical grade. Deionized water was used for the preparation and dilution of the solutions.

\subsection{Preparation of SPI}

To prepare soy protein with high solubility, the method of $\mathrm{Li}$ et al. (2007) was used..$^{21}$ Briefly, defatted soybean flake, which had been prewashed with aqueous alcohol, was suspended in deionized water and adjusted to $\mathrm{pH} 7.0$ with $2.0 \mathrm{M} \mathrm{NaOH}$. After stirring for $1 \mathrm{~h}$, the suspension was centrifuged at $8000 \mathrm{~g}$ for $30 \mathrm{~min}$ at $4{ }^{\circ} \mathrm{C}$. Then, the $\mathrm{pH}$ of the supernatant was adjusted to 4.5 with $2.0 \mathrm{M} \mathrm{HCl}$. The protein precipitate collected by centrifugation at $8000 \mathrm{~g}$ for $30 \mathrm{~min}$ at $4{ }^{\circ} \mathrm{C}$ was redissolved with deionized water and adjusted to $\mathrm{pH} 7.0$ with $2.0 \mathrm{M} \mathrm{NaOH}$. Protein solution was then dialyzed and freeze dried. Proximate analysis showed that the dried powder had protein contents of $92.47 \%(N \times 6.25)$ and ash contents of $3.01 \%$ on a dry basis.

\subsection{Preparation of SPI and GA stock solutions}

SPI and GA stock solutions were prepared by dispersing a certain amount of biopolymer powder in distilled water under gentle stirring at room temperature $\left(25 \pm 1{ }^{\circ} \mathrm{C}\right)$ for $2 \mathrm{~h}$ and left overnight at $4{ }^{\circ} \mathrm{C}$ to allow complete hydration of macromolecules. SPI $(7.0 \%, \mathrm{w} / \mathrm{w})$ dispersion was centrifuged at $10000 \mathrm{~g}$ for 30 min at $4{ }^{\circ} \mathrm{C}$ and the protein content of the supernatants was determined by Lowry's method. ${ }^{22} \mathrm{NaN}_{3}(0.02 \%$, w/v) was added to inhibit bacteria growth.

\subsection{Protein solubility}

SPI solutions diluted to $0.5 \%(\mathrm{w} / \mathrm{w})$ were adjusted to $\mathrm{pH} 3.0-7.0$ with $1 \mathrm{M} \mathrm{HCl}$ and stirred for $30 \mathrm{~min}$. The suspension was centrifuged at $10000 \mathrm{~g}$ for $30 \mathrm{~min}$ at $20{ }^{\circ} \mathrm{C}$. Protein content in the supernatant determined using Lowry method. Protein solubility was the percentage of the original protein that was solubilized. All experiments were carried out at least three times.

\subsection{Turbidity assay}

SPI and GA solutions were diluted and well mixed with a total biopolymer concentration of $0.1 \%(\mathrm{w} / \mathrm{w})$. Control SPI solution was also assayed at a concentration of $0.05 \%(\mathrm{w} / \mathrm{w})$. The turbidity was changed by adding $0.01-2.0 \mathrm{M} \mathrm{HCl}(\mathrm{pH}$ range of 7.0-2.0). Turbidity titration curves were measured with a UV2450 spectrophotometer (Shimadzu, Kyoto, Japan) at $600 \mathrm{~nm}$ using plastic cuvettes (1 cm path length) according to Dong et al. (2013). ${ }^{20}$

\subsection{Zeta potential measurement}

SPI solution was diluted to $1.0 \%(\mathrm{w} / \mathrm{w})$ and mixed with GA solution $(1.0 \%, \mathrm{w} / \mathrm{w})$ in equal volume. The zeta potential samples (SPI, GA and mixtures) were prepared by adjusting to desired $\mathrm{pH}$ and then diluted to $0.1 \%(\mathrm{w} / \mathrm{w})$ with the same $\mathrm{pH}$ value. Zeta potential measurement was performed on Zetasizer Nano-ZS instrument (Malvern Instruments, British) at $25{ }^{\circ} \mathrm{C}$. The equilibration time for each sample was $90 \mathrm{~s}$.

\subsection{Emulsion preparation}

Aqueous biopolymer solutions and $10 \%(\mathrm{w} / \mathrm{v})$ soybean oil were initially emulsified using a high-shear homogenizer (FA25 model, Fluko Equipment Co., Ltd., Shanghai, China) at $10000 \mathrm{rpm}$ for $1 \mathrm{~min}$, and then homogenized at $40 \mathrm{MPa}$ with three passes using a high-pressure homogenizer (AH 2010, ATS 
Engineering, Inc., Shanghai, China). As shown in Fig. 1, emulsions were prepared in three different ways. (I) SPI and GA solutions were well mixed. The mixed solutions were adjusted to pH 3.0-7.0 with 1.0 M HCl. Then the mixtures were stirred for $1 \mathrm{~h}$ before emulsification. (II) SPI and GA solutions were well mixed. Then $\mathrm{pH}$ was adjusted to 4.0 with $1.0 \mathrm{M} \mathrm{HCl}$ to form complex. SPI-GA emulsion was prepared by homogenizing the complex with soy oil. The emulsion was divided into five small aliquots and then adjusted $\mathrm{pH}$ to 3.0-7.0 with $1.0 \mathrm{M} \mathrm{HCl}$, respectively. (III) GA solutions was slowly added to SPIstabilized emulsion (1.0\% SPI, $20 \%$ soybean oil, w/v). The resultant emulsion was divided into five small aliquots and then adjusted $\mathrm{pH}$ to $3.0-7.0$ with $1.0 \mathrm{M} \mathrm{HCl}$, respectively. SPIstabilized emulsions as controls were also separately prepared in the above different ways. All the final emulsions contained $10 \%(\mathrm{w} / \mathrm{v})$ oil, $0.5 \%(\mathrm{w} / \mathrm{v})$ SPI with or without $0.5 \%(\mathrm{w} / \mathrm{v}) \mathrm{GA}$.

\subsection{Particle size measurement}

The particle size measurement of the emulsion sample was carried out on a Mastersizer 2000 Laser Particle Size Analyzer (Malvern Instruments, Malvern, UK). The parameters of refractive index were set to 1.470 for soybean oil and 1.330 for deionized water. The emulsions were diluted ten times using deionized water or $1.0 \%(\mathrm{w} / \mathrm{v})$ sodium dodecyl sulfate (SDS) solution before determinations. The particle size was reported as the volume mean diameter $\left(d_{43}\right)$.

\subsection{Flocculation index (FI) measurement}

The calculation of flocculation was used for quantitative evaluation of flocculation degree of different samples. Flocculation index was calculated as follows:

$$
\text { FI }(\%)=\left[\left(d_{43} \text { in water } / d_{43} \text { in SDS }\right)-1.0\right] \times 100
$$

where $d_{43}$ in water and $d_{43}$ in SDS were the volume mean diameter determined in water and in 1\% SDS, respectively.

\subsection{Determination of percentage of adsorbed proteins and polysaccharides}

Percentage of adsorbed proteins and polysaccharides were determined according to the method described by Tangsuphoom and Coupland (2009) with slight modification. ${ }^{23}$ Emulsions were centrifuged at $18000 \mathrm{~g}$ for $60 \mathrm{~min}$ at room temperature inducing the separation of a cream layer at the top and an aqueous phase at the bottom of the tube. The aqueous phase was carefully withdrawn using a syringe and passed
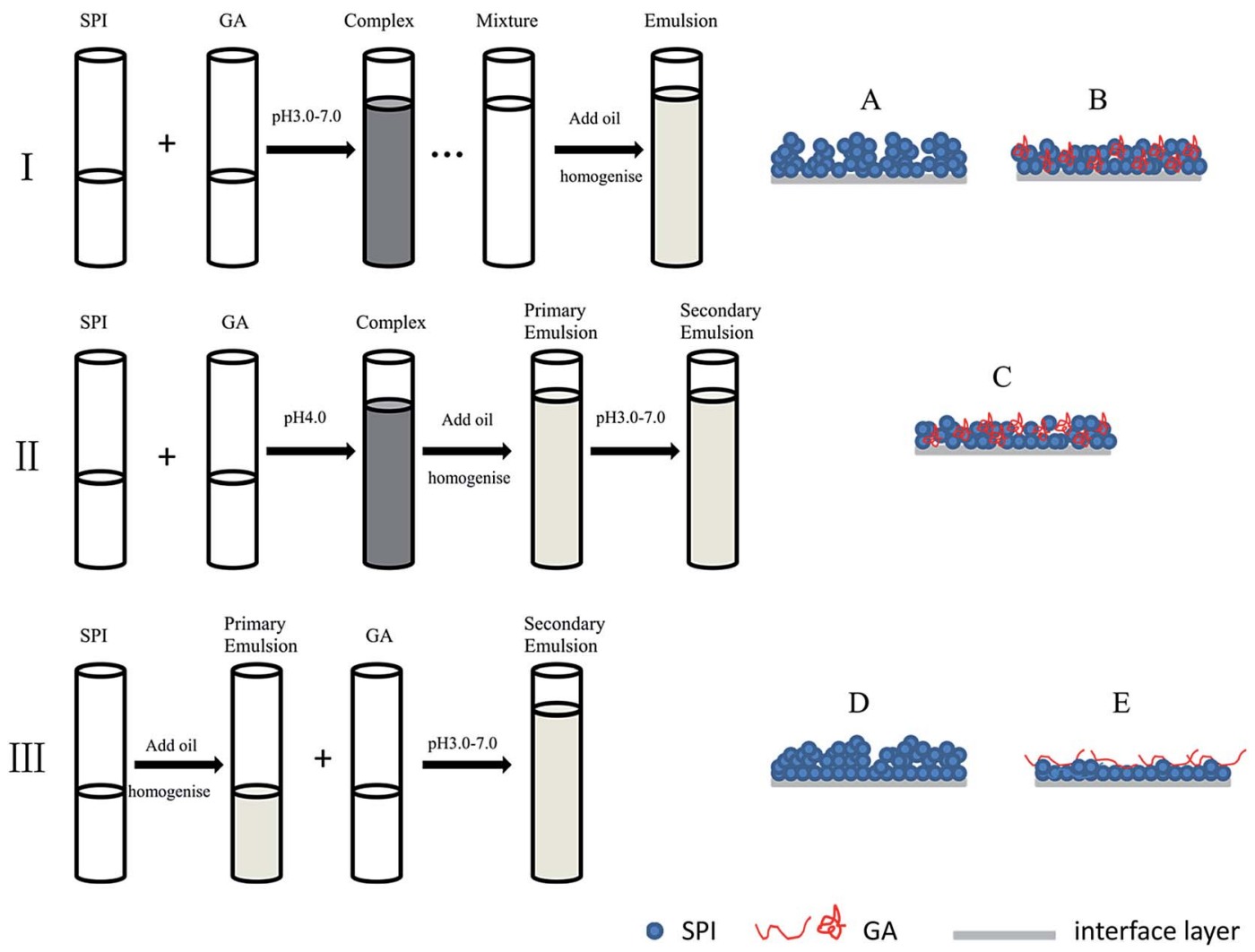

Fig. 1 Schematic representation of different preparation routes (I, II, III) for emulsions. (A-E) were the situation of interface absorption at acidic pHs. (A) Soy proteins aggregates absorbed on the interface for SPI-control emulsion I; (B) soy proteins and GA complexes absorbed on the interface for SPI-GA emulsion I; (C) soy proteins and GA complexes on the interface for SPI-GA emulsion II (similar to B); (D) protein monolayer absorbed on the surface at $\mathrm{pH} 7.0$, then with the decrease of $\mathrm{pH}$, protein dissolved in water deposited gradually on the monolayer protein for $\mathrm{SPI}-$ control emulsion III; (E) protein monolayer absorbed on the surface at $\mathrm{pH} 7.0$, then with the decrease of pH, soy proteins-GA mixtures deposited gradually for SPI-GA emulsion III. 
through a $0.22 \mu \mathrm{m}$ filter and protein and polysaccharide concentrations were determined by Lowry method and phenol/ sulfuric acid method, respectively. ${ }^{22,24}$

The percentage of adsorbed protein and polysaccharide was calculated as follows:

$$
\operatorname{AP}(\%)=\left(C_{\mathrm{i}}-C_{\mathrm{s}}\right) / C_{\mathrm{i}} \times 100
$$

where AP was adsorbed protein (or polysaccharide), $C_{\mathrm{i}}$ was the initial protein (or polysaccharide) concentration of samples used for the emulsion preparation, $C_{\mathrm{s}}$ was the protein (or polysaccharide) concentration of the aqueous phase after centrifugation.

\subsection{Rheological measurement}

Rheological measurement according to Peng, Hua, Chen, Kong, and Zhang (2016) was performed on the controlled-stress rheometer AR1000 (TA Instrument, New Castle, UK) with a parallel plate geometry (50 $\mathrm{mm}$ diameter and $1 \mathrm{~mm}$ gap) at $25{ }^{\circ} \mathrm{C} .{ }^{25}$ The viscosity was determined as the function of shear rates (ranging from 0 to $100 \mathrm{~s}^{-1}$ ) and fitted to a power law model as follows:

$$
\eta=k \gamma^{n-1}
$$

where $\eta$ was the viscosity (Pa s), $\gamma$ was the shear rate $\left(\mathrm{s}^{-1}\right), k$ was the consistency index ( $\left.\mathrm{Pa} \mathrm{s}^{n}\right), n$ was the index of flow behavior: $n$ $<1$ for shear-thinning fluid, $n=1$ for Newtonian fluid and $n>1$ for shear-thickening fluid.

\subsection{Confocal laser scanning microscopy (CLSM) measurement}

Fresh emulsion was mixed with FITC-Nile Red mixture solution (40 $\mu \mathrm{l}$ of $0.1 \%(\mathrm{w} / \mathrm{w})$ FITC and $0.1 \%(\mathrm{w} / \mathrm{w})$ Nile Red per $\mathrm{ml}$ emulsion), and the stained mixture was stirred for $30 \mathrm{~min}$ in the dark. The samples were examined using confocal laser scanning microscope (LSM 710) with a $\times 20$ objective. The images were collected using 488 and $543 \mathrm{~nm}$ excitation wavelength for FITC and Nile Red, respectively.

\subsection{Creaming index (CI) measurement}

$3.0 \mathrm{ml}$ of fresh emulsion was added into sample bottle and stored at room temperature. The total height of emulsion $\left(H_{\mathrm{t}}\right)$ was $3.5 \mathrm{~cm}$. The height of aqueous layer at the bottom $\left(H_{\mathrm{a}}\right)$ was recorded until the fourteenth day. Creaming index was calculated as follows:

$$
\mathrm{CI}(\%)=\left(H_{\mathrm{a}} / H_{\mathrm{t}}\right) \times 100
$$

\subsection{Data analysis}

All experiments were performed in triplicate. The data were analyzed using SPSS for Windows (version 13.0, SPSS Inc. Chicago, IL) for one-way ANOVA. Data were expressed as mean values \pm standard deviations. Significant differences were determined by comparing the means and to identify $P<0.05$.

\section{Results and discussion}

\subsection{Turbidity analysis}

Changes to turbidity as a function of $\mathrm{pH}$ for SPI or SPI-GA mixed solutions were given in Fig. 2. On addition of $\mathrm{HCl}$ with different concentrations to the SPI solution ( $\mathrm{pH} 7.0$ ), it was observed that the curve showed a rapid rise in turbidity near $\mathrm{pH}$ approximately 5.5 and kept the maximum turbidity of about 0.4 at $\mathrm{pH}$ 4.0-5.0. Turbidity is a function of particle shape, refractive index, size distribution and specific gravity. Here the observed rapid rise in turbidity was thought to be associated with formation of protein aggregates as a result of reduced electrostatic repulsive forces between individual proteins, which could also be seen from the low nitrogen solubility (8.07\% for $\mathrm{pH} 4.0$ and $4.36 \%$ for $\mathrm{pH} 5.0$ ).

$\mathrm{pH}$ affected the charge densities and thus the complexing behavior of SPI and GA, as shown in Fig. 2. Acidification of SPIGA mixture from neutral $\mathrm{pH}$ first led to the formation of soluble complexes at $\mathrm{pH} 4.35\left(\mathrm{pH}_{\mathrm{c}}\right)$. Above $\mathrm{pH}_{\mathrm{c}}$, electrostatic repulsive forces inhibited the formation of complexes, and the turbidity remained at the baseline. With further acidification to $\mathrm{pH} 3.82$ $\left(\mathrm{pH}_{\Phi}\right)$, an abrupt increase in $\mathrm{OD}_{600}$ was observed, indicating the formation of insoluble complexes. The turbidity reached the maximum at $\mathrm{pH} 3.43\left(\mathrm{pH}_{\mathrm{opt}}\right)$ and decreased rapidly as $\mathrm{pH}$ continued to drop. It could be seen that the addition of GA could keep SPI-GA mixture remain at very low turbidity when $\mathrm{pH}$ is higher than 4.0, which might be helpful to the resultant emulsions. Liu, Elmer, Low, and Nickerson (2010) studied $\beta$ lactoglobulin and GA complex coacervation and reported that a maximum interaction between the two biopolymers occurred at $\mathrm{pH} 4.2$ for the $1: 1$ mixture. $^{26}$

\subsection{Surface charge analysis}

SPI dispersions showed gradually less negative values with decreasing $\mathrm{pH}$ as shown in Fig. 3, eventually becoming positive below the pI of SPI. With the addition of GA, at pH 6.0-7.0, there was little interaction between SPI and GA due to the both negative charges as evidenced by -20 to $-22 \mathrm{mV} \zeta$ potential values. At $\mathrm{pH} 4.0$ and 5.0, the dispersion yielded negative $\zeta$

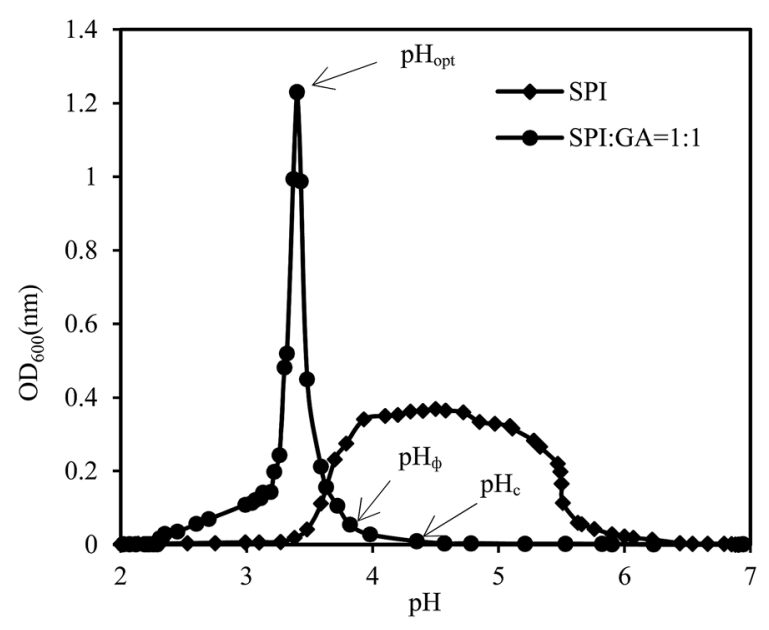

Fig. 2 Turbidity curve as a function of $\mathrm{pH}$ for SPI-GA 


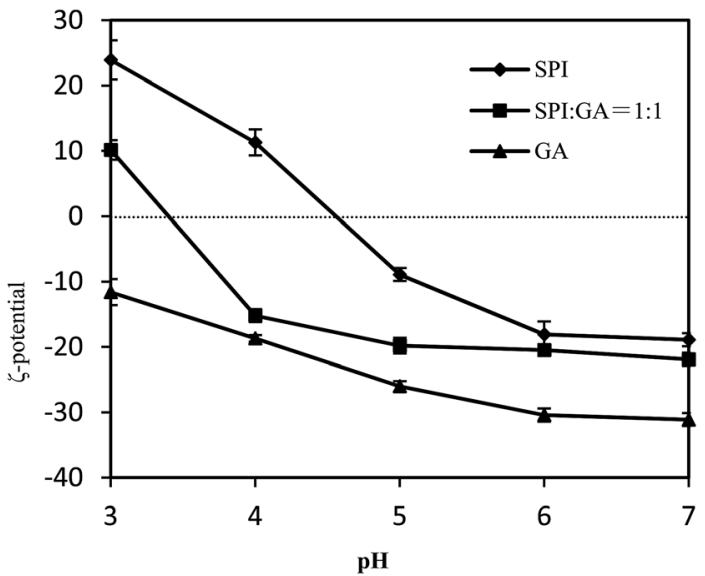

Fig. 3 -Potential values as a function of $\mathrm{pH}$ for SPI-GA.

potential due to electrostatic complexation between SPI and GA. ${ }^{12}$ This was particularly evident at $\mathrm{pH} 4.0$ and 5.0, where SPI would be expected to precipitate sans added GA. When $\mathrm{pH}$ was decreased to 3.0, SPI-GA dispersion showed positive $\zeta$ potential (about $10 \mathrm{mV}$ ) due to the increased charges of SPI.

\subsection{Fresh emulsion characteristics: influence of $\mathrm{pH}$ and order of addition to oil-water interface}

Three routes were investigated for the preparation of emulsions $(10 \%(\mathrm{w} / \mathrm{v})$ oil, $0.5 \%(\mathrm{w} / \mathrm{v})$ SPI with/without $0.5 \%(\mathrm{w} / \mathrm{v}) \mathrm{GA})$. In emulsions I, SPI solution with/without GA were first adjusted $\mathrm{pH}$ followed by homogenization with oil; in emulsions II, the oil was directly emulsified with mixed SPI-GA solution at $\mathrm{pH} 4.0$ to form the 'mixed emulsions', then $\mathrm{pH}$ was adjusted to prepare the different emulsions; in emulsions III, GA was added to a SPIstabilized emulsion followed by $\mathrm{pH}$ adjustment. The schematic representation of the three preparation methods was shown in Fig. 1.

As summarized in Table 1, a key finding was that $\mathrm{pH}$ adjustment before or after homogenization with oil greatly influenced the droplet size and stability of the emulsions whether for the SPI emulsion or SPI-GA emulsion. It indicated that the order of $\mathrm{pH}$ adjustment resulted in different conformations of soy proteins and the adsorption morphology on the interfacial layers. ${ }^{27}$ The addition of GA could partly improve the emulsion (emulsion III), with the smallest $d_{43}$ values in the presence of SDS.

3.3.1 Droplet size (in the absence or presence of SDS). Significant differences in the droplet size of SPI or SPI-GA emulsion were evident with the change of $\mathrm{pH}$ from 7.0 to 3.0 no matter which preparation route was applied. Table 1 shows the $d_{43}$ values of droplets in different emulsions prepared at different conditions, at varying $\mathrm{pH}$ (3.0-7.0), determined using water or $1 \%$ SDS as the dispersing solvent. The $d_{43}$ of deflocculated droplets in the emulsions, e.g., in the presence of SDS, can reflect ability of the proteins to help dispersion of oil phase into an aqueous medium. As shown in Table 1 and Fig. 4, the

Table 1 Mean particle size values ( $d_{43}$, in water or $\left.1 \% \mathrm{SDS}\right)$, flocculation index ( $\left.\mathrm{FI}\right)$ and percentage of absorbed protein (AP 1 ) and polysaccharides $\left(\mathrm{AP}_{2}\right)$ in fresh emulsions prepared in different ways ${ }^{a}$

\begin{tabular}{|c|c|c|c|c|c|c|c|}
\hline \multicolumn{2}{|c|}{ Emulsion type } & $\mathrm{pH}$ & \multicolumn{2}{|l|}{$d_{43}(\mu \mathrm{m})$} & FI $(\%)$ & $\mathrm{AP}_{1}(\%)$ & $\mathrm{AP}_{2}(\%)$ \\
\hline & & 4 & $124.40 \pm 1.51^{\mathrm{a}}$ & $2.54 \pm 0.86^{\mathrm{a}}$ & $47.97 \pm 0.28^{\mathrm{f}}$ & $94.98 \pm 1.00^{\mathrm{de}}$ & \multirow{3}{*}{-} \\
\hline & & 5 & $119.90 \pm 1.43^{\mathrm{b}}$ & $1.23 \pm 0.01^{\mathrm{b}}$ & $96.47 \pm 0.93^{b}$ & $95.80 \pm 1.00^{\mathrm{cd}}$ & \\
\hline & & 6 & $17.59 \pm 0.23^{\mathrm{n}}$ & $1.13 \pm 0.02^{\mathrm{d}}$ & $14.56 \pm 0.25^{1}$ & $61.42 \pm 0.99^{\mathrm{kl}}$ & \\
\hline & \multirow{4}{*}{ SPI/GA } & 4 & $95.34 \pm 9.03^{\mathrm{d}}$ & $1.22 \pm 0.03^{\mathrm{c}}$ & $77.14 \pm 5.58^{\mathrm{de}}$ & $98.17 \pm 0.36^{\mathrm{b}}$ & $69.47 \pm 2.19^{c}$ \\
\hline & & 5 & $131.90 \pm 6.12^{\mathrm{a}}$ & $1.28 \pm 0.07^{\mathrm{bc}}$ & $102.05 \pm 8.99^{\mathrm{ab}}$ & $96.06 \pm 0.11^{\mathrm{d}}$ & $66.96 \pm 0.13^{\mathrm{d}}$ \\
\hline & & 6 & $39.16 \pm 0.32^{g}$ & $1.01 \pm 0.01^{\mathrm{f}}$ & $37.78 \pm 0.32^{\mathrm{h}}$ & $90.76 \pm 0.04^{\mathrm{f}}$ & $5.40 \pm 0.09^{j}$ \\
\hline & & 7 & $1.34 \pm 0.01^{\mathrm{q}}$ & $0.97 \pm 0.01^{\mathrm{g}}$ & $0.38 \pm 0.01^{\mathrm{q}}$ & $69.57 \pm 0.18^{\mathrm{j}}$ & $3.89 \pm 0.09^{k}$ \\
\hline \multirow[t]{2}{*}{ II } & \multirow[t]{2}{*}{ SPI/GA } & 3 & $89.17 \pm 1.45^{\mathrm{d}}$ & $1.06 \pm 0.01^{\mathrm{e}}$ & $82.12 \pm 0.89^{\mathrm{d}}$ & $97.63 \pm 0.18^{b}$ & $97.27 \pm 0.31^{\mathrm{a}}$ \\
\hline & & 4 & $92.80 \pm 2.27^{\mathrm{d}}$ & $1.07 \pm 0.01^{\mathrm{e}}$ & $85.73 \pm 1.79^{c}$ & $98.17 \pm 0.36^{\mathrm{b}}$ & $69.47 \pm 2.19^{c}$ \\
\hline & \multirow{4}{*}{ SPI } & 4 & $18.93 \pm 0.25^{1}$ & $2.45 \pm 0.09^{\mathrm{a}}$ & $6.74 \pm 0.39^{\mathrm{n}}$ & $98.69 \pm 0.19^{b}$ & \multirow{4}{*}{-} \\
\hline & & 5 & $29.65 \pm 0.96^{\mathrm{i}}$ & $2.54 \pm 0.23^{\mathrm{a}}$ & $10.66 \pm 0.69^{\mathrm{m}}$ & $88.56 \pm 0.56^{\mathrm{g}}$ & \\
\hline & & 6 & $6.39 \pm 0.01^{\circ}$ & $0.99 \pm 0.01^{\mathrm{g}}$ & $5.44 \pm 0.01^{\mathrm{o}}$ & $60.98 \pm 1.88^{\mathrm{kl}}$ & \\
\hline & & 7 & $1.07 \pm 0.01^{\mathrm{r}}$ & $0.85 \pm 0.01^{\mathrm{i}}$ & $0.25 \pm 0.01^{\mathrm{r}}$ & $62.85 \pm 0.75^{\mathrm{k}}$ & \\
\hline & \multirow[t]{5}{*}{ SPI/GA } & 3 & $20.88 \pm 0.18^{\mathrm{k}}$ & $0.77 \pm 0.01^{\mathrm{j}}$ & $26.19 \pm 0.27^{\mathrm{j}}$ & $95.48 \pm 0.03^{\mathrm{e}}$ & $56.58 \pm 0.11^{\mathrm{e}}$ \\
\hline & & 4 & $19.24 \pm 0.51^{1}$ & $0.84 \pm 0.01^{\mathrm{i}}$ & $21.96 \pm 0.81^{\mathrm{k}}$ & $96.05 \pm 0.08^{\mathrm{d}}$ & $14.20 \pm 0.30^{\mathrm{h}}$ \\
\hline & & 5 & $23.80 \pm 0.66^{\mathrm{j}}$ & $0.83 \pm 0.01^{\mathrm{i}}$ & $27.54 \pm 0.90^{\mathrm{i}}$ & $96.10 \pm 0.22^{\mathrm{cd}}$ & $14.85 \pm 0.04^{\mathrm{i}}$ \\
\hline & & 6 & $2.92 \pm 0.16^{\mathrm{p}}$ & $0.64 \pm 0.01^{\mathrm{k}}$ & $3.60 \pm 0.27^{\mathrm{p}}$ & $95.91 \pm 0.12^{\mathrm{d}}$ & $0.06 \pm 0.01^{1}$ \\
\hline & & 7 & $0.67 \pm 0.01^{\mathrm{s}}$ & $0.63 \pm 0.01^{\mathrm{k}}$ & $0.05 \pm 0.01^{\mathrm{t}}$ & $79.12 \pm 0.53^{\mathrm{h}}$ & $0.05 \pm 0.01^{1}$ \\
\hline
\end{tabular}

\footnotetext{
${ }^{a}$ Means within a column with different letters are significantly different $(P<0.05)$.
} 

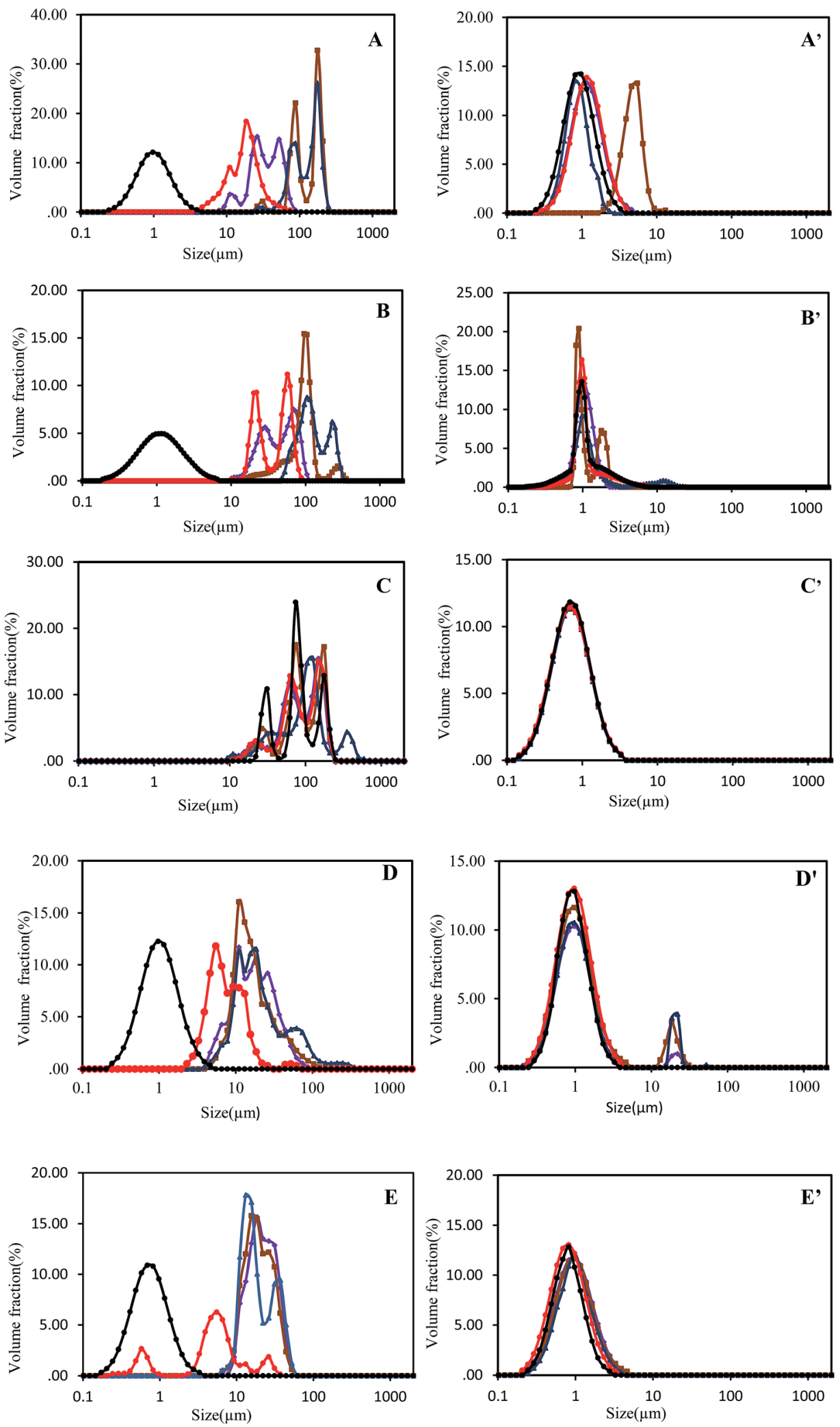

Fig. $4 \mathrm{pH}$-dependent $\left(\mathrm{pH} 3 \diamond, \mathrm{pH} 4 \mathbf{\square}, \mathrm{pH} 5 \Delta, \mathrm{pH} 6 \bullet, \mathrm{pH} 7 \bullet\right.$ ) particle size distributions of SPI and SPI/GA emulsions prepared by method I (A, $\mathrm{A}^{\prime}$ for SPI emulsions and B, $\mathrm{B}^{\prime}$ for SPI/GA emulsions), method II (C, C' for SPI/GA emulsions) and method III (D, D' for SPI emulsions and E, E' for SPI/ GA emulsions), as determined with water $(A-E)$ or $1 \% \operatorname{SDS}\left(A^{\prime}-E^{\prime}\right)$. 
particle size distributions were dominated by a single peak at about $1 \mu \mathrm{m}\left(d_{43}\right.$ in $1 \%$ SDS $)$ except SPI-GA emulsion I at pH 4 .

For SPI-control emulsions, the particle size values differ significantly with the emulsifying routes and $\mathrm{pH}$. At neutral $\mathrm{pH}$, the particle size $\left(d_{43}\right)$ and FI for the emulsions prepared by different routes were similar, while at acidic $\mathrm{pH}$ they are quite different for the emulsions prepared by different routes. Due to the low solubility of soy proteins at $\mathrm{pH} 4.0-5.0$, the SPI-control emulsion I owned bigger particle size about $120 \mu \mathrm{m}$. Combined with $d_{43}$ values in the presence of SDS, it could be seen that the droplets were flocculated severely especially at pH 5.0 with FI of $96.47 \%$. The flocculation of the droplets might be due to the hydrophobic interactions among soy proteins. ${ }^{28}$ For emulsion I or III at pH 3.0 and $\mathrm{pH} 6.0-7.0$, the charged SPI prevented flocculation via electrostatic repulsion. Droplet sizes were smallest (ca. 1.07-1.08 $\mu \mathrm{m}$ ) at pH 7.0 further away from the pI of SPI. At pH 6.0 and 3.0, average droplet sizes were $c a$. 6.39-33.53 $\mu \mathrm{m}$ due to reduction of like-charge repulsion between droplets. It was interestingly found that SPI-control emulsion III had smaller droplet size and FI, which were significantly different from SPI-control emulsion I. This indicated that the preparation route greatly influenced the obtained emulsions.

Both SPI-control emulsions III and SPI-GA emulsions III owned smaller average droplet size ranged from 0.67 to 29.65 $\mu \mathrm{m}$ at $\mathrm{pH}$ 3.0-7.0. This suggested that SPI emulsions obtained by homogenizing at neutral $\mathrm{pH}$ were more resistant to $\mathrm{pH}$ variations compared with those (emulsions I) adjusting $\mathrm{pH}$ followed by homogenization, which could be reflected from the obviously different particle size, especially at $\mathrm{pH} 4.0$ and 5.0. The result was similar with the work from Azarikia and Abbasi (2016), who investigated the effects of different preparation methods on whey protein-tragacanth emulsions and found that "layer by layer" emulsions had lower particle size compared with "mixed emulsions". ${ }^{29}$

The SPI-GA emulsion I and III at $\mathrm{pH} 7.0$ had $d_{43}$ values of $1.34 \mu \mathrm{m}$ and $0.67 \mu \mathrm{m}$, respectively, while SPI-GA emulsion I with $\mathrm{pH}$ below 6.0 also had larger $d_{43}$ values and FI. The presence of $0.5 \%$ GA for the mixed-layer emulsion II resulted in the higher $d_{43}$ values and FI at pH 3.0-7.0. Compared with SPIcontrol emulsion III, $d_{43}$ values of SPI-GA emulsion III showed a slight decrease at pH 5.0 and 6.0, combined with the increase of interfacial protein adsorption.

3.3.2 Protein and polysaccharide adsorption at the oil/ water interface. The addition of polyelectrolytes to existing protein-stabilized interfaces seems to have been less frequently investigated than the direct adsorption of protein-polyelectrolyte complexes. Nevertheless, the process of sequential addition can be expected to have a strong influence on the overall adsorption behavior, as well as on the thickness and mechanical strength of the composite interfacial film.

As shown in Table 1, when no GA was present at $\mathrm{pH} 7.0$ in the emulsion I or III, the adsorption percentage of SPI onto the droplets was around $60.82-62.85 \%$. With the presence of GA in emulsions I or III, at $\mathrm{pH} 7.0,6.0$ or 3.0 , there were more SPI adsorbed (69.57-96.32\%), while there was little adsorption of GA onto the droplet surface at $\mathrm{pH} 7.0$ or 6.0. Khouryieh, Puli, Williams, and Aramouni (2015) reported that xanthan gum does not bind on the whey protein-coated droplet surface at neutral $\mathrm{pH}$, hence will not alter the size of the droplet. ${ }^{30}$ Jourdain, Leser, Schmitt, Michel, and Dickinson (2008) also found no change of droplet charge and size in mixed emulsion containing sodium caseinate and different concentrations of dextran sulfate at neutral $\mathrm{pH}$, suggesting that there was no electrostatic attraction between sodium caseinate and dextran sulfate. ${ }^{27}$ Compared at pH 4.0 and 5.0, GA adsorption percentages were significantly higher in SPI-GA emulsion I (66.96-69.47\%) than those in SPIGA emulsion III (14.20-14.85\%), which resulted in the higher $d_{43}$ values. It was noticeable that at $\mathrm{pH} 3.0$, there were more proteins and polysaccharides adsorbed on the interfaces, which

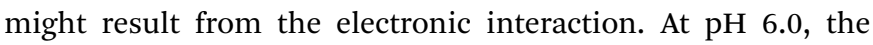
protein adsorption ratio increased from $60.98 \%$ to $95.91 \%$ due to the presence of GA with the polysaccharides adsorption ratio of only $0.06 \%$. It seemed that the presence of GA promoted the adsorption of SPI on the interfaces, which might due to the repulsion interaction among them, depletion flocculation. ${ }^{31}$

3.3.3 Microstructure of the emulsions by CLSM. In contrast to conventional light microscopy, confocal laser scanning microscopy restricts the illumination to a single point, the image, thus, showed a two-dimensional section of the specimen. In Fig. 5, the different types of emulsions were visualized. The oil phase was colored in red and the soy protein phase appeared green. The light green circles around the droplets clearly indicated the protein layer surrounding the red oil phase. The light green hue or the orange hue reflected that both lipid and protein phase were mixed. As expected, the droplet microstructure of these emulsions considerably varied with the types of the emulsion (the order of homogenization and $\mathrm{pH}$ adjustment, with or without the presence of GA). For the emulsion I and III, it can be observed that most of the droplets were presented in the separated and unflocculated form at neutral pH, especially at $\mathrm{pH}$ 7.0, whereas at $\mathrm{pH}$ 6.0, slight flocculation was observed. It could be seen clearly that the droplets in the emulsions at acidic $\mathrm{pH}$ flocculated greatly, especially at $\mathrm{pH} 4.0$ and 5.0. For emulsions I, soy protein solutions were adjusted to the corresponding $\mathrm{pH}$, followed by homogenization. At $\mathrm{pH}$ 4.0-5.0, near SPI's pI, uncontrolled aggregation of the proteins occurred due to charge neutralization, which dominated by attractive van der Waals and hydrophobic forces.

In the case of a protein and polysaccharide mixture, CLSM images showed large orange hue intensive areas at pH 3.0-6.0 (Fig. 5B and C), which also means that the oil droplet flocculation in SPI-GA emulsion I and II were greater than SPI-GA emulsion III. This result was consistent with the findings related to flocculation index (Table 1). At neutral pH, except SPIGA emulsion II, the emulsions showed a more uniform structure. The nonuniform structure of SPI-GA emulsion II may explained by bridging flocculation because of the introduction of salt ions in the process of emulsion preparation with $\mathrm{pH}$ adjustment from 4.0 to 7.0. Salt ions could promote flocculation between droplets via electrostatic screening. ${ }^{12}$ Additionally, the emulsions with or without GA presented similar microstructures: aggregations and large flocs were observed in emulsions at acidic pHs, no obvious aggregations at neutral $\mathrm{pH}$. 

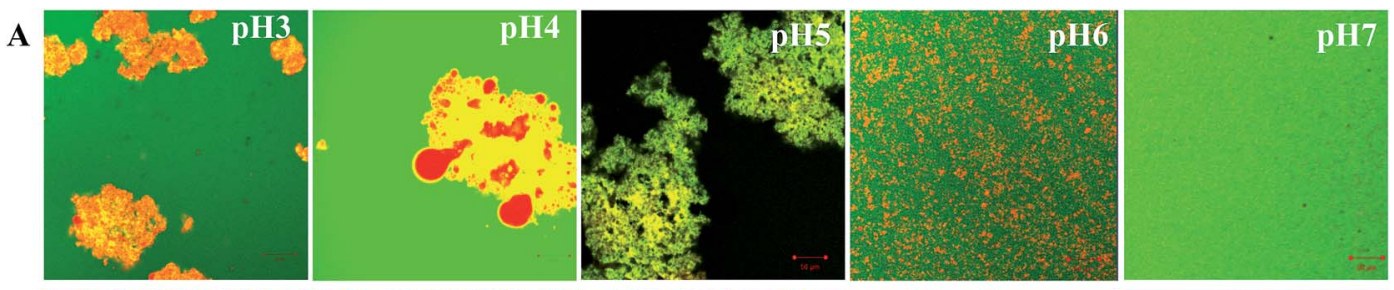

B
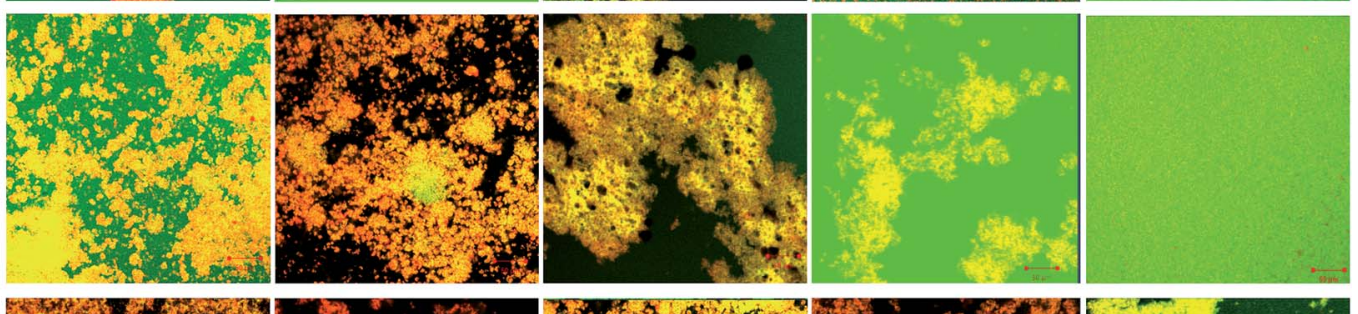

C
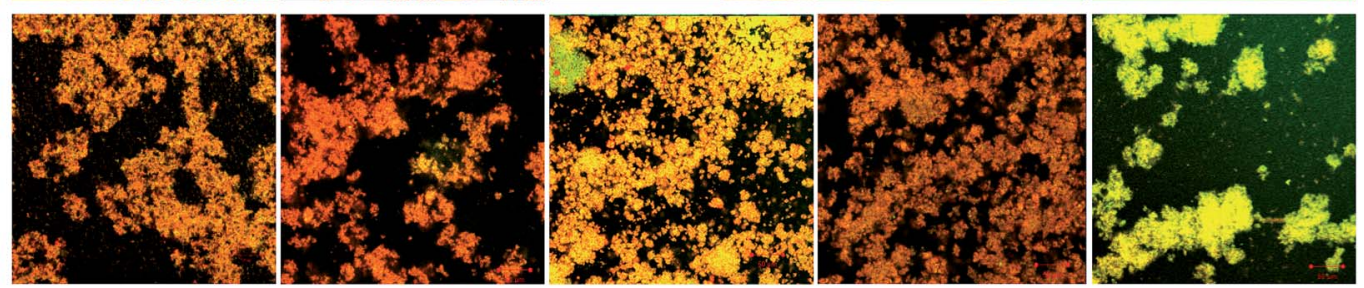

D
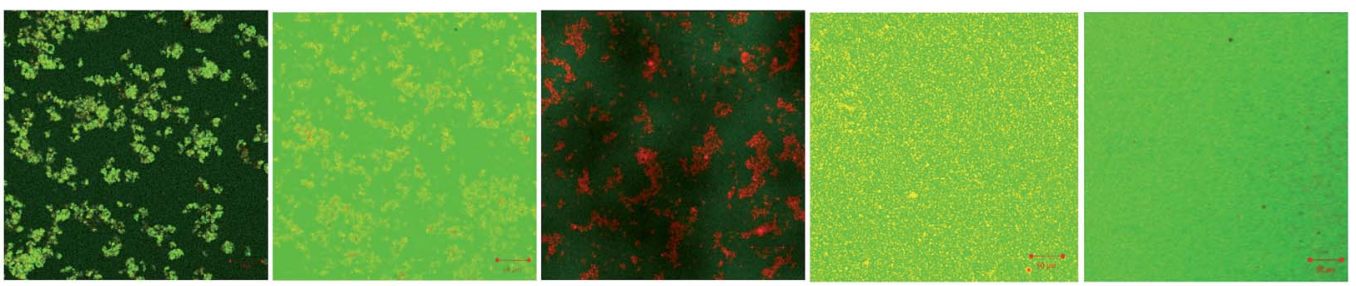

E
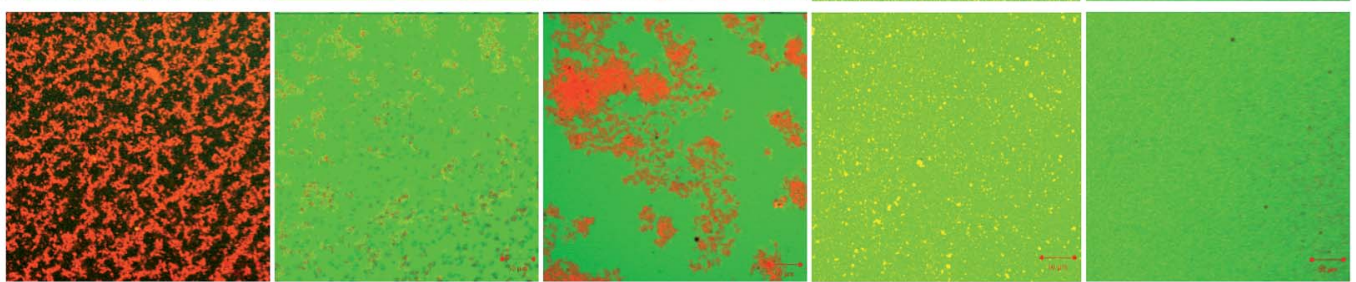

Fig. 5 CLSM images of SPI (A, D prepared by method I, III) and SPI/GA emulsions (B, C and E prepared by method I, II and III) produced from FITClabeled soy protein and Nile Red-labeled soy oil at different $\mathrm{pH}$. The changes of $\mathrm{pH}$ values in $\mathrm{B}, \mathrm{C}, \mathrm{D}$ and $\mathrm{E}$ were the same as $\mathrm{A}$.

3.3.4 Rheological properties of the emulsions. The rheological properties of the emulsions stabilized by SPI with/ without GA were investigated (Fig. 6). All test emulsions were showed shear-thinning behavior, which can also deduced from the flow behavior index $n(n<1)$. However, the $k$ values were significantly affected by different $\mathrm{pH}$ and process. For SPI control emulsions, the $k$ values were higher at $\mathrm{pH} 4.0$ and 5.0 than other pHs, which were similar between SPI-control emulsion I and III. This indicated that acidic pH closing to the isoelectric point increases the viscosity of the emulsions, which may due to the generation of large protein aggregates. Compared to SPI-control emulsions, the SPI-GA emulsions III owned lower $k$ values at $\mathrm{pH} 4.0$ and 5.0 but the $k$ values showed increasing intendency at $\mathrm{pH}$ 3.0. The change of rheological properties in the presence of GA may due to the increase of protein solubility at $\mathrm{pH} 4.0$ and 5.0 leading to the decreasing viscosity. However, the protein solubility was reduced because of the formation of insoluble SPI-GA complex at $\mathrm{pH}$ 3.0, which increased the emulsion viscosity. According to Fig. 6, the SPIGA emulsion III possessed the smallest $k$ value at $\mathrm{pH} 4.0,5.0$ and 6.0. This may be due to the lower degree of flocculation of droplet (Table 1) and the better protein solubility (Fig. 1).

\subsection{Emulsion stability/creaming stability}

Fig. 7 shows the changes in percentage of creaming index (CI\%) for all the test emulsions, upon storage up to 2 weeks. For SPIcontrol emulsions I, distinctly visual creaming occurred after storage of 1 day at $\mathrm{pH} 4.0$ and 5.0, while the presence of GA improved greatly the creaming stability at $\mathrm{pH}$ 4.0. This might be due to the formation of soluble SPI-GA complex. ${ }^{32,33}$ Surprisingly, the creaming stability for SPI-GA emulsion I at pH 5.0 was not improved with $\mathrm{CI} \%$ of about $50 \%$ after 1 day storage. At $\mathrm{pH}$ 3.0, SPI-control emulsion I had better creaming stability compared with SPI-GA emulsion I. This could be explained that at $\mathrm{pH}$ 3.0, soy proteins carried more positive charges and there were more protein and polysaccharides absorbed on the 

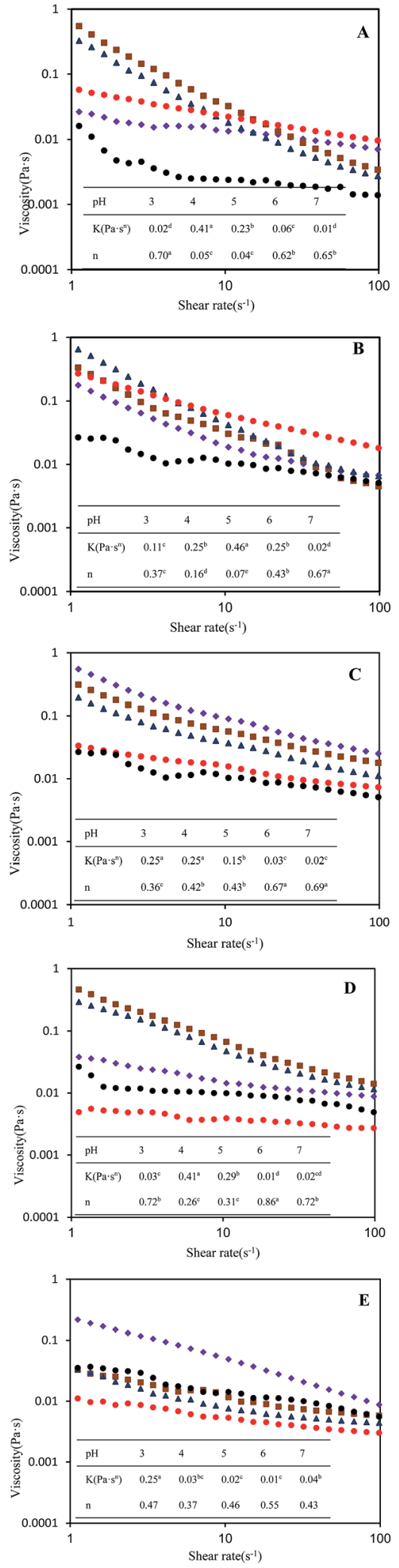

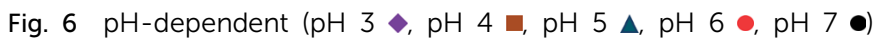
rheological properties of SPI and SPI/GA emulsions prepared by method I (A for SPI emulsion and B for SPI/GA emulsion), method II (C for SPI/GA emulsion) and method III (D for SPI emulsion and E for SPI/ $\mathrm{GA}$ emulsion). $K$ is the consistency index $\left(\mathrm{Pa} s^{n}\right)$, and $n$ is the flow behavior index. Means within a row with different letters are significantly different $(p<0.05)$.
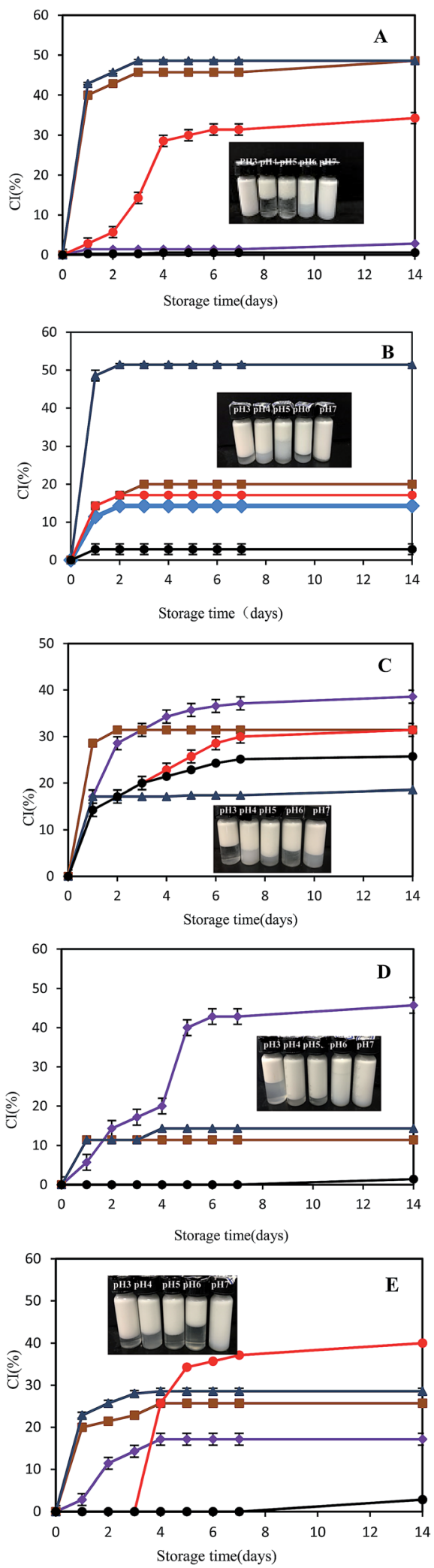

Fig. $7 \mathrm{pH}$-dependent $\left(\mathrm{pH} 3 \bullet, \mathrm{pH}_{4} \backsim, \mathrm{pH}_{5} \Delta, \mathrm{pH} 6 \bullet, \mathrm{pH} 7 \bullet\right.$ ) creaming index of SPI and SPI/GA emulsions prepared by method I (A for SPI emulsion and B for SPI/GA emulsion), method II (C for SPI/GA emulsion) and method III (D for SPI emulsion and E for SPI/GA emulsion). The photographs were visual images of emulsions after 14 days storage. 
droplets. At $\mathrm{pH}$ 6.0, with the presence of GA (emulsion I), protein adsorption percentage increased to $90.76 \%$. Thus, the bottom of the emulsions became less turbid which might be due to the depletion flocculation as seen from the increase of FI (from $14.56 \%$ to $37.78 \%$ ).

For SPI-GA emulsion II, the creaming stability decreased at $\mathrm{pH}$ 3.0, 6.0 and 7.0, while it increased at $\mathrm{pH} 4.0$ and 5.0 compared with SPI-control emulsion I. This indicated that mixed-layers emulsions prepared by soluble SPI-GA complex at $\mathrm{pH} 4.0$ were less resistant to $\mathrm{pH}$ variations, especially $\mathrm{pH}$ below 3.0 or above 6.0. As seen from Table 1, SPI-GA emulsions II at $\mathrm{pH}$ 3.0-7.0 all had a high protein adsorption ratio in a range of 95.26-99.08\%. When $\mathrm{pH}$ decreased from $\mathrm{pH} 4.0$ to 3.0 , GA adsorption ratio increased from $69.47 \%$ to $97.27 \%$. With the increase of $\mathrm{pH}$ from 4.0 to $6.0-7.0$, GA adsorption ratio decreased to about $32 \%$. This was due to the stronger or weaker electrostatic interactions between SPI and GA since soy proteins became more positive at $\mathrm{pH} 3.0$ and more negative above $\mathrm{pH} 6.0$ (Fig. 3). Compared with SPI-GA emulsions I, there were more polysaccharides adsorption for SPI-GA emulsions II at pH 6.07.0 , which indicated the occurrence of the mixed layers on the droplet.

For SPI-control emulsion III, the emulsions were first prepared by homogenization at $\mathrm{pH}$ 7.0, then $\mathrm{pH}$ was adjusted. Comparably, SPI emulsions III at pH 4.0-7.0 all had a high creaming stability, with no distinct creaming at $\mathrm{pH}$ 6.0-7.0 and $\mathrm{CI}$ of $10 \%$ at $\mathrm{pH} 4.0-5.0$ after 14 days storage. Only emulsions at pH 3.0 were not very stable. After 14 days, the SPI emulsion III at pH 3.0 destabilized as evidenced by the population of flocs $\geq 100 \mu \mathrm{m}$ in diameter (data not shown). Similar to SPI-GA emulsions I and SPI-control emulsions III, SPI-GA emulsion III at $\mathrm{pH} 7.0$ was quite stable and exhibited no distinct creaming upon storage up to 8 days (Fig. 7B and E). For SPI-GA emulsions III, about 56.58\% GA adsorbed to the droplet surfaces at $\mathrm{pH} 3$, about $14 \%$ GA at $\mathrm{pH} 4-5$, but not at pH 6 and 7, which was attributed to electrostatic attraction between anionic groups on the GA and cationic groups on the SPI. With the presence of GA, $\mathrm{CI}$ at $\mathrm{pH} 3.0$ was remarkably decreased as compared to the SPIcontrol emulsion III.

\section{Conclusions}

The objective of this study was to examine the influence of different preparation routes and $\mathrm{pH}$ on the stability of SPIcoated or SPI-GA coated emulsion droplets. The results have shown that the sequence of adjusting $\mathrm{pH}$ and homogenizing soy oil with soy proteins greatly influenced the droplet size and the stability of the above referred emulsions. SPI-coated emulsions III are more stable to droplet flocculation which indicated that the adsorbed soy proteins on the $\mathrm{O} / \mathrm{W}$ interfaces are more resistant to aggregation compared with the aqueous soy proteins in the preparation route I.

GA may either increase or decrease the stability of SPI-GA stabilized emulsions depending on the preparation routes and $\mathrm{pH}$. In the absence of GA, soy proteins emulsions I were unstable to droplet flocculation over the range $\mathrm{pH} 4-5$ which was attributed to their relatively low droplet charge. At a $\mathrm{pH}$ value slightly below the pI of SPI, the soluble complexes between SPI and GA formed, which increases the stability of SPI-GA emulsions I at pH 4. The emulsion III showed much lower flocculation rate, and the viscosity of SPI-GA stabilized emulsion decreased significantly, even near protein isoelectric point. This study can be an available reference for the choice of emulsion preparation routes, which would be helpful for the development of emulsion products containing SPI under acidic $\mathrm{pH}$.

\section{Acknowledgements}

The work was financially supported by National Natural Science Foundation of China (No. 31201380) and 863 Program (Hi-tech research and development program of China, No. 2013AA102204-3).

\section{References}

1 D. J. McClements and Y. Li, Adv. Colloid Interface Sci., 2010, 159, 213-228.

2 D. J. McClements, Curr. Opin. Colloid Interface Sci., 2004, 9, 305-313.

3 D. I. Comas, J. R. Wagner and M. C. Tomas, Food Hydrocolloids, 2006, 20, 990-996.

4 B. Yin, W. Deng, K. Xu, L. Huang and P. Yao, J. Colloid Interface Sci., 2012, 380, 51-59.

5 D. Guzey and D. J. McClements, Adv. Colloid Interface Sci., 2006, 128, 227-248.

6 E. Dickinson, Colloids Surf., B, 2010, 81, 130-140.

7 R. Pongsawatmanit, T. Harnsilawat and D. J. McClements, Colloids Surf., A, 2006, 287, 59-67.

8 E. Dickinson, Soft Matter, 2008, 4, 932-942.

9 E. Bouyer, G. Mekhloufi, I. L. Potier and T. D. F. D. Kerdaniel, J. Colloid Interface Sci., 2011, 354, 467-477.

10 M. Corredig, N. Sharafbafi and E. Kristo, Food Hydrocolloids, 2011, 25, 1833-1841.

11 E. Dickinson, Food Hydrocolloids, 2011, 25, 1966-1983.

12 T. Tran and D. Rousseau, Food Hydrocolloids, 2013, 30, 382392.

13 L. Jourdain, C. Schmitt, M. E. Leser, B. S. Murray and E. Dickinson, Langmuir, 2009, 25, 10026-10037.

14 F. Weinbreck, M. Minor and C. G. de Kruif, J. Microencapsulation, 2004, 6, 667-697.

15 E. Dickinson, Food Hydrocolloids, 2003, 17, 25-39.

16 S. Jung, P. C. Roussel and J. L. Briggs, J. Am. Oil Chem. Soc., 2004, 81, 953-960.

17 M. Keerati-u-rai and M. Corredig, J. Agric. Food Chem., 2010, 58, 9171-9180.

18 T. Mahendran, P. A. Williams, G. O. Phillips, S. Al-Assaf and T. C. Baldwin, J. Agric. Food Chem., 2008, 56, 9269-9276.

19 Y. Dror, Y. Cohen and R. Yerushalmi-Rozen, J. Polym. Sci., Part B: Polym. Phys., 2006, 44, 3265-3271.

20 D. Dong, Y. Hua, Y. Chen, X. Kong, C. Zhang and Q. Wang, J. Agric. Food Chem., 2013, 61, 3934-3940.

21 X. Li, Y. Li, Y. Hua, A. Qiu, C. Yang and S. Cui, Food Chem., 2007, 104, 1410-1417. 
22 O. H. Lowry, N. J. Rosebrough, A. L. Farr and R. J. Randall, J. Biol. Chem., 1951, 193, 265-275.

23 N. Tangsuphoom and J. N. Coupland, Food Hydrocolloids, 2009, 23, 1801-1809.

24 M. Dubois, K. A. Gilles, J. K. Hamilton, P. A. Rebers and F. Smith, Anal. Chem., 1956, 28, 350-356.

25 W. Peng, X. Kong, Y. Chen, C. Zhang, Y. Yang and Y. Hua, Food Hydrocolloids, 2016, 52, 301-310.

26 S. Liu, C. Elmer, N. H. Low and M. T. Nickerson, Food Res. Int., 2010, 43, 489-495.

27 L. Jourdain, M. E. Leser, C. Schmitt, M. Michel and E. Dickinson, Food Hydrocolloids, 2008, 22, 647-659.
28 Y. Chang and D. J. McClements, Food Hydrocolloids, 2015, 51, 252-260.

29 F. Azarikia and S. Abbasi, Food Hydrocolloids, 2016, 59, 2634.

30 H. Khouryieh, G. Puli, K. Williams and F. Aramouni, Food Chem., 2015, 167, 340-348.

31 T. Harnsilawat, R. Pongsawatmanit and D. J. McClements, J. Agric. Food Chem., 2006, 54, 5540-5547.

32 A. Ye, J. Gilliland and H. Singh, Food Hydrocolloids, 2011, 25, 1677-1686.

33 T. Vinayahan, P. A. Williams and G. O. Phillips, Biomacromolecules, 2010, 11, 3367-3374. 